\title{
Treatment strategies in Alzheimer's disease: a review with focus on selenium supplementation
}

\author{
Jan Aaseth • Jan Alexander • Geir Bjørklund • Knut Hestad • \\ Petr Dusek $\cdot$ Per M. Roos • Urban Alehagen
}

Received: 24 July 2016/Accepted: 25 July 2016/Published online: 16 August 2016

(C) The Author(s) 2016. This article is published with open access at Springerlink.com

\begin{abstract}
Alzheimer's disease (AD) is a neurodegenerative disorder presenting one of the biggest healthcare challenges in developed countries. No effective treatment exists. In recent years the main focus of $\mathrm{AD}$ research has been on the amyloid hypothesis, which postulates that extracellular precipitates of beta amyloid $(\mathrm{A} \beta)$ derived from amyloid precursor protein (APP) are responsible for the cognitive impairment seen in AD. Treatment strategies have been to reduce $\mathrm{A} \beta$ production through
\end{abstract}

J. Aaseth · K. Hestad

Department of Research, Innlandet Hospital Trust, Brumunddal, Norway

J. Aaseth · K. Hestad

Department of Public Health, Hedmark University of Applied Sciences, Elverum, Norway

J. Alexander

Norwegian Institute of Public Health, Oslo, Norway

J. Alexander

Norwegian University of Life Sciences (NMBU),

Ås, Norway

G. Bjørklund

Council for Nutritional and Environmental Medicine,

Mo i Rana, Norway

P. Dusek

Department of Neurology and Center of Clinical Neuroscience, Charles University in Prague, 1st Faculty of Medicine and General University Hospital in Prague, Prague, Czech Republic inhibition of enzymes responsible for its formation, or to promote resolution of existing cerebral $\mathrm{A} \beta$ plaques. However, these approaches have failed to demonstrate significant cognitive improvements. Intracellular rather than extracellular events may be fundamental in AD pathogenesis. Selenate is a potent inhibitor of tau hyperphosphorylation, a critical step in the formation of neurofibrillary tangles. Some selenium (Se) compounds e.g. selenoprotein $\mathrm{P}$ also appear to protect APP against excessive copper and iron

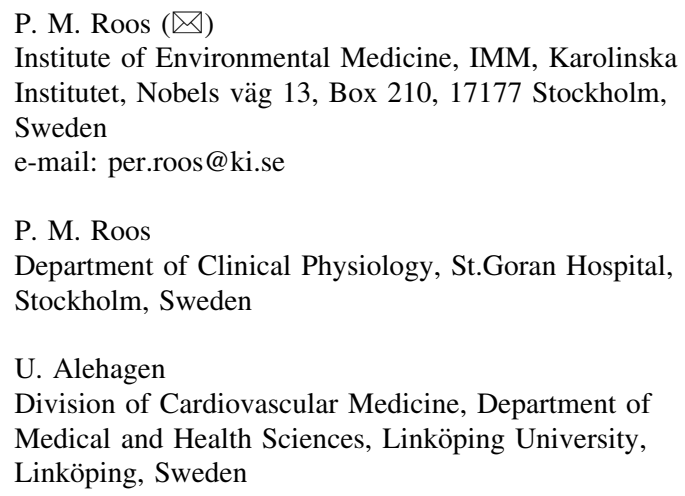


deposition. Selenoproteins show anti-inflammatory properties, and protect microtubules in the neuronal cytoskeleton. Optimal function of these selenoenzymes requires higher $\mathrm{Se}$ intake than what is common in Europe and also higher intake than traditionally recommended. Supplementary treatment with $\mathrm{N}$-acetylcysteine increases levels of the antioxidative cofactor glutathione and can mediate adjuvant protection. The present review discusses the role of Se in $\mathrm{AD}$ treatment and suggests strategies for $\mathrm{AD}$ prevention by optimizing selenium intake, in accordance with the metal dysregulation hypothesis. This includes in particular secondary prevention by selenium supplementation to elderly with mild cognitive impairment.

Keywords Alzheimer's disease · Copper · Iron · Neuroinflammation · Transmitters $\cdot$ Selenium

\section{Introduction}

Alzheimer's disease (AD) is a neurodegenerative disorder prevalent in old age. In developed countries $13 \%$ of people over 65 suffer from $\mathrm{AD}$ according to the Alzheimer's Association. Projected AD prevalence indicate 100 million patients globally by 2050 (Alzheimer's 2015), leading to considerable economic burden for society and suffering for patients and caregivers. AD is classified as genetic or sporadic. Genetic AD is an early-onset hereditary disease representing 1-2\% of diagnosed cases (Campion et al. 1999). In genetic AD mutated genes coding for amyloid precursor protein (APP; chromosome 21) are found, and presenilin 1 (PS1; chromosome 14) and presenilin 2 (PS2; chromosome 1$)$, promote amyloid beta $(\mathrm{A} \beta)$ formation. The vast majority of patients suffer from sporadic $\mathrm{AD}$.

Many sporadic AD patients are carriers of the e4 allele of the ApoE gene (apolipoprotein E; chromosome 19). The mechanism whereby ApoE e4 allele increases AD risk is largely unknown (Hardy and Selkoe 2002). Recent research has unmasked minor mutations which mediate an intermediate $\mathrm{AD}$ risk. Most genes associated with AD roughly cluster within three metabolic pathways: lipid metabolism, inflammatory response, and endocytosis (Giri et al. 2016). Aging is considered the principal risk factor for sporadic $\mathrm{AD}$, followed by hypertension, dyslipidemia, metabolic syndrome and diabetes (Drachman 2014).
In the present paper, we first discuss treatment strategies based on traditional hypotheses of $\mathrm{AD}$ pathogenesis: (a) the transmitter hypothesis, (b) the metabolic hypothesis, (c) the tau protein hypothesis, and (d) the amyloid cascade hypothesis. Then we address the metal-based hypothesis of neuroinflammation which opens new therapeutic possibilities (Ward et al. 2014). Oxidative stress from copper $(\mathrm{Cu})$ and iron $(\mathrm{Fe})$ toxicity is implicated in the metal hypothesis of $\mathrm{AD}$ pathogenesis. In this context we discuss a putative therapeutic or preventive role of selenium (Se) supplementation, evoked by a Swedish study reporting improved vitality and reduced signs of inflammation and oxidative stress after Se yeast and coenzyme $\mathrm{Q}_{10}$ intervention in an elderly population (Alehagen et al. 2013).

\section{Traditional hypotheses}

The transmitter hypothesis

Cholinergic neurons projecting to the hippocampus in the temporal lobe are affected early in AD. Deficient spatial memory in rodents has been mapped to grid cells that collect sensory signals in the entorhinal cortex (Hafting et al. 2005). The language problems and declining verbal recall characterizing AD patients are presumed to arise from dysfunction in hippocampal regions (Lim et al. 2012), and these cells are influenced by cholinergic modulation (Konishi et al. 2015). Loss of cholinergic inputs to the hippocampus is a well characterized abnormality in AD. Decreased acetylcholine release combined with reductions in nicotinic and muscarinic receptors in the cortex and hippocampus of AD brains examined post-mortem has been seen (Tata et al. 2014). Acetylcholinesterase inhibitors used in $\mathrm{AD}$ treatment act by increasing acetylcholine bioavailability at synaptic loci. Unfortunately, these enzyme inhibitors are not capable of reversing $\mathrm{AD}$, nor slowing disease progression (Wallace and Bertrand 2013). Memantine acts on the $\mathrm{N}$-methyl-D-aspartate (NMDA) receptors blocking glutamate activity (Parsons et al. 2007). A dysfunction of glutamatergic transmission has been hypothesized to be involved in the neurodegeneration in $\mathrm{AD}$. Memantine appears to improve this dysfunction, and has been associated with a moderate decrease in clinical deterioration, with a small positive effect on 
cognition (Areosa et al. 2005). However, although transmitter dysfunction is seen in $\mathrm{AD}$, it can be suspected that the initial biochemical lesions involve structural and functional impairment of vital proteins responsible for transmitter transport and neuronal integrity.

The metabolic hypothesis

Clinical studies suggest that the metabolic syndrome, including hypertension, obesity, and insulin resistance or type 2 diabetes (T2DM), is a significant risk factor for AD development (Kivipelto et al. 2005). Disturbed hippocampal insulin signalling is likely present in $\mathrm{AD}$ (Hokama et al. 2014). Increased insulin resistance and oxidative stress with elevated levels of advanced glycation end products (AGE) are proposed mechanisms by which metabolic syndrome may increase the risk of $\mathrm{AD}$ ( $\mathrm{Li}$ et al. 2012). A recent study in mice indicated an association between amount of hypothalamic beta-amyloid fragments, neuroinflammation and peripheral glucose intolerance (Clarke et al. 2015). Reactive oxygen species (ROS) and tumor necrosis factor alpha also contribute to this intriguing syndrome combination (Lourenco et al. 2013). As the molecular mechanisms in $\mathrm{AD}$ and in insulin resistance seem related, it is tempting to assume that drugs used for T2DM treatment e.g. the glitazones could be protective also in AD. A phase II trial with rosiglitazone for 6 months reported improvements in memory and attention in patients who did not possess an e4 allele of the ApoE gene (Risner et al. 2006), but a phase III rosiglitazone trial failed (Gold et al. 2010). However, insulin resistance is associated with increased AGE formation, decreased protection against oxygen radicals (Aaseth and Stoa-Birketvedt 2000) and raised levels of methylglyoxal (MGA) (Thornalley et al. 1999). These substances are all neurotoxic and possess high reactivity toward thiol (SH) groups such as the numerous microtubule $\mathrm{SH}$ groups in the neuronal cytoskeleton. Increased MGA concentrations in cerebrospinal fluid have been reported in AD (Kuhla et al. 2005), and may contribute to tau disintegration and tangle formation.

The tau hyperphosphorylation hypothesis

Tau is a neuronal, microtubulus-associated protein, which in healthy brains regulates microtubuli dynamics
(Yuraszeck et al. 2010). Derangements of microtubuli and of the neuronal cytoskeleton provide clues to the understanding of $\mathrm{AD}$ pathogenesis. Intact microtubuli are involved in transport of essential substances from neuronal bodies to synaptic structures. Phosphorylation regulates tau protein binding to microtubuli. Under physiological conditions the tau protein remains soluble, but hyperphosphorylation compromises its normal functions (Mehta et al. 2015), and leads to formation of insoluble neurofibrillary tangles, which are bundles of paired helical protein filaments. Such excessive phosphorylation in $\mathrm{AD}$ must result from an imbalance between phosphorylating kinases and de-phosphorylating phosphatases. Increased expression of active kinases adjacent to neurofibrillary tangles has been described in AD (Hochgrafe et al. 2015). One of these kinases and a potential drug target is cyclin-dependent kinase 5 (CDK5). Increased intracellular calcium in AD brains is associated with CDK5 activation (Shukla et al. 2012). CDK5 inhibitors have demonstrated neuroprotective properties in in vitro and in vivo AD models (Zimmer et al. 2012). Sodium selenate also reduces tau phosphorylation, both in cell cultures and in AD mouse models (Corcoran et al. 2010b). Administration of selenate to rodents produces cognitive improvements and reduced neurodegeneration (van Eersel et al. 2010). In these models selenate is presumably converted to specific selenoproteins including glutathione peroxidases (Fig. 1), which may attenuate the intracellular burden of ROS and thereby protect microtubuli in the cytoskeleton.

The amyloid cascade hypothesis

The amyloid precursor protein (APP) is a glycosylated protein that is uniformly found in cell membranes, most abundant in the brain. A hypothesis claims that the membrane bound protein APP acts as a $\mathrm{Cu}$ chaperone, thereby exerting cytoprotective functions (Prohaska and Gybina 2004). Apparently, APP is involved in synaptic repair and in cell signaling (Priller et al. 2006). Substances synthesized in the cell bodies of neurons must be transported outward to the distal synapses. It has been found that APP can mediate interactions that facilitate this transport (Jonsson et al. 2012). A mutation in APP makes the protein more resistant against degradation and protects against cognitive decline (Jonsson 2013). APP is 


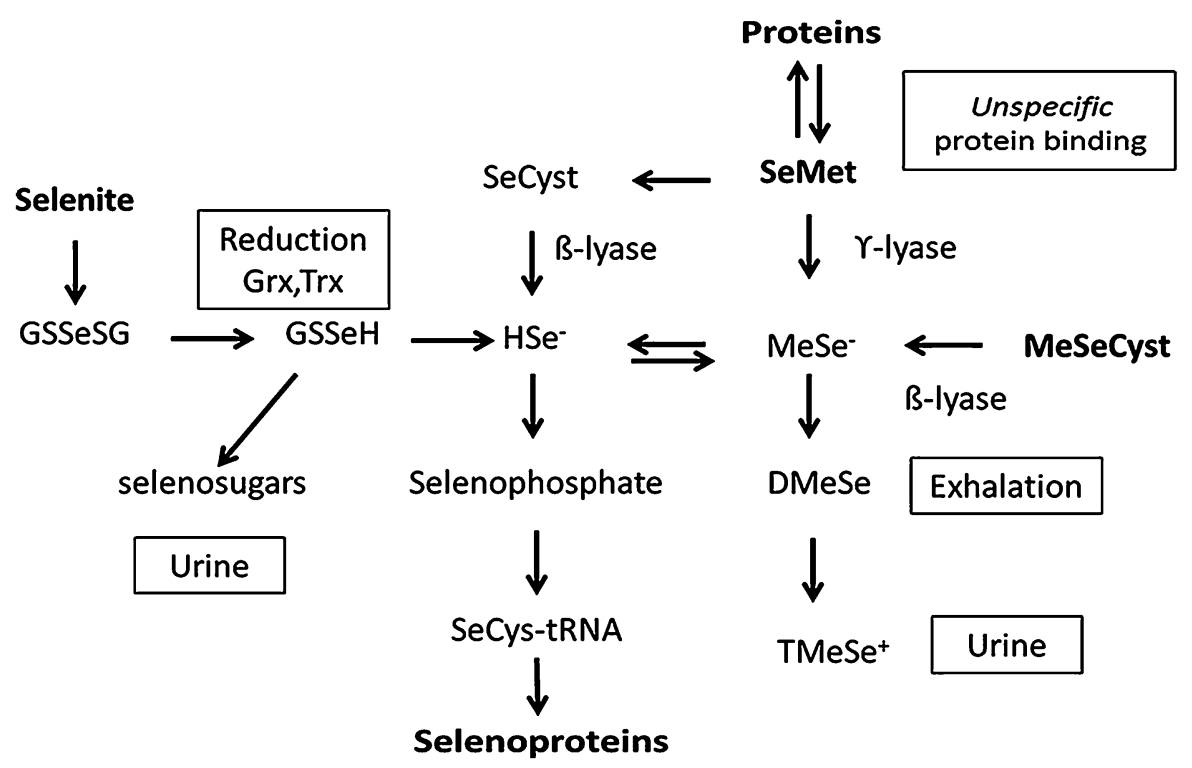

Fig. 1 Biotransformation of selenite and seleno-amino acids to selenide, selenoproteins and excretable metabolites. The reduction of selenite is facilitated by GSH, glutaredoxins, glutathione reductase and/or thioredoxin (Trx) and TrxR. It consumes reducing equivalents, NADPH. Selenate that is transported into cells by an anion transport mechanism (Jager et al. 2016), is also reduced to selenide, but the intracellular reduction of selenate to selenite is less efficient and not fully understood. Hydrogen selenide $\left(\mathrm{HSe}^{-}\right)$and methyl selenide $\left(\mathrm{MeSe}^{-}\right)$react with

degraded into several peptides by the three intracellular enzymes: $\alpha-, \beta-$, and $\gamma$-secretases. Soluble cleavage products might also have cytoprotective effects on synaptic structures. Several isoforms of the A $\beta$-peptide degradation product exist (Mawuenyega et al. 2013). In dominant genetic forms of $A D$, the disease is thought to be due to over production of $A \beta$, or an increase in $A \beta 42$ to $A \beta 40$ ratio (Kumar-Singh et al. 2006). The $A \beta$-peptide with 42 amino acids, $A \beta$ (1-42), usually called $A \beta$, is an insoluble variant that is prevalent in both sporadic and genetic $\mathrm{AD}$, and constitutes the amyloid core in the precipitated plaques (Gaggelli et al. 2006).

Active immunization (vaccination) with either $\mathrm{A} \beta$ (1-42) or smaller $A \beta$ fragments has been evaluated in transgenic mouse models of AD. Such vaccination will generally activate the phagocytotic capacity of microglia. The early human tests using a fulllength $\mathrm{A} \beta$ with an added adjuvant resulted in serious adverse events including aseptic meningoencephalitis (Gilman et al. 2005). Later vaccines were composed from a shorter $A \beta$ fragment in an attempt oxygen and thiols and complete the redox-cycle. Selenium can be incorporated specifically into selenoproteins via pathways from selenide and the synthesis of selenophosphate. Selenomethioneine can be converted to $\mathrm{MeSe}^{-}$or to selenocysteine via the transsulfuration pathway or unspecifically replace its sulfur analogue in proteins. Among excretory metabolites are selenosugars and at high doses dimethylselenide and trimethyl selenonium ion $\left(\mathrm{TMSe}^{+}\right)$(Alexander 2014)

to avoid side effects. A vaccine denoted CAD106 has reached the clinical phases of development (Wiessner et al. 2011), showing specific antibody response in a majority of treated patients without serious adverse reactions, but without significant therapeutic effect. Other vaccines are in preclinical stages (Panza et al. 2014).

Passive immunization involves i.v. administration of antibodies directed specifically against $\mathrm{A} \beta$. Studies in transgenic animals have shown that passive immunization reduces cerebral amyloid load. Bapineuzumab and solanezumab are monoclonal antibodies against $\mathrm{A} \beta$ fragments (Tayeb et al. 2013). Both drugs have reached advanced stages of clinical development (Salloway et al. 2014), but without producing significant clinical improvement in humans (Tayeb et al. 2013). So far, immunotherapy has not proven successful in arresting the cognitive decline in AD patients. Since APP and its physiological degradation products exert cytoprotective functions, immunotherapy is not expected to become a treatment of choice. 
The neuroinflammation hypothesis

As discussed above, the insoluble APP derivative A $\beta$ appears to be responsible for plaque formation (Castello and Soriano 2014), and $\mathrm{A} \beta$ may induce oxidative stress and microinflammation. An early hypothesis was that suppressing of inflammation could arrest precipitation of $\mathrm{A} \beta$ and cognitive decline. This therapeutic exploration began with the observation that several nonsteroidal anti-inflammatory drugs (NSAIDs) decreased $\mathrm{A} \beta$ levels in animal models. Ibuprofen, sulindac and flurbiprofen were considered as promising drugs (Du et al. 2014b). The mechanism of action of NSAIDs was ascribed to their inhibition of cyclooxygenases leading to reduced inflammation and thus reduced $\mathrm{A} \beta$ precipitation. Yet ibuprofen was ineffective for AD treatment in clinical trials (Pasqualetti et al. 2009), and independent research has failed to show positive results of treatment with NSAIDs in AD. Interestingly however, some NSAIDs possess copper-chelating properties (Puranik et al. 2016) and further research on possible therapeutic effects of selected NSAIDs in relation to the metal hypothesis of neuroinflammation is justified. Also the key role of microglia in neuroinflammatory processes deserves further attention (Xiang et al. 2006). It has been found that microglia surrounds $\mathrm{A} \beta$ plaques (ElAli and Rivest 2016). Furthermore, it has been reported that Se abrogates stress-induced microglial cell migration (Dalla Puppa et al. 2007). Further research is necessary to explore if Se attenuates the inflammatory cascade associated with cognitive decline in AD.

\section{The metal-based hypothesis of neuroinflammation}

Copper and iron dysregulation in $\mathrm{AD}$

It has been reported that $\mathrm{Fe}$ and $\mathrm{Cu}$ accumulate in $\mathrm{AD}$ plaques, and this deposition appears to promote the progression of the $A \beta$ cascade (Altamura and Muckenthaler 2009). Inside of neurons $\mathrm{Fe}$ and $\mathrm{Cu}$ binding to hyperphosphorylated tau protein precede the formation of intracellular tangles (Barnham and Bush 2014). The presence of free $\mathrm{Fe}(\mathrm{II})$ or $\mathrm{Cu}(\mathrm{I})$ species will induce deleterious Fenton reactions with ROS generation and microinflammation (Ward et al. 2015).

Experiments indicate that ceruloplasmin $(\mathrm{CP}), \mathrm{a} \mathrm{Cu}$ containing enzyme with ferroxidase activity, protects
CNS from Fe(II)-mediated injury (Patel et al. 2002). Torsdottir et al. (2011) found that the CP ferroxidase activity was lower in mild cognitive impairment (MCI) patients than in controls although CP concentrations were similar in both groups (Torsdottir et al. 2011). They explained the discrepancy by a deficient $\mathrm{CP} \mathrm{Cu}$ incorporation, while the synthesis of apo-CP was unaffected. Brewer et al. (2010) found that CP activity but not amount of $\mathrm{CP}$ was lower in $\mathrm{AD}$ patients than in controls (Brewer et al. 2010). Here, it is pertinent to recapitulate clinical and neuropathological findings in aceruloplasminemia, a rare hereditary disorder caused by mutation in the $\mathrm{CP}$ gene and characterized by absent serum $\mathrm{CP}$ activity with $\mathrm{Fe}$ deposition in the brain leading to neuropsychiatric symptoms (Kono 2013). Although aceruloplasminemia patients presented five to ten times higher brain tissue Fe concentrations than controls (Morita et al. 1995), no brain amyloid or tau protein precipitation was seen (Gonzalez-Cuyar et al. 2008; Kaneko et al. 2012). Cognitive symptoms in aceruloplasminemia patients include executive dysfunction suggesting fronto-striatal involvement, rather than hippocampal impairment (Kono 2013).

Sparks and Schreurs (2003) reported that minor $(0.12 \mathrm{mg} / \mathrm{L}) \mathrm{Cu}$ excess in drinking water together with cholesterol in the chow for 10 weeks accelerated the formation of amyloid deposits around cerebral vessels and induced learning deficits in a rabbit model (Sparks and Schreurs 2003). Subsequently, Squitti et al. (2011) argued that the level of free serum $\mathrm{Cu}$ in $\mathrm{AD}$ patients has a predictive value in assessing disease progression (Squitti et al. 2011). When discussing the Cu hypothesis for $\mathrm{AD}$, some characteristics of Wilson disease (WD) may be relevant (Brewer et al. 2010). In WD, Cu levels in the brain are increased by a factor of 5-10 (Horoupian et al. 1988), but the characteristic AD pathology is not present (Meenakshi-Sundaram et al. 2008). Cognitive testing in WD reveals deficit in the executive domain rather than in episodic memory (Iwanski et al. 2015). Together with the findings in aceruloplasminemia, this absence of AD pathology in WD brains suggests that an overall elevation of $\mathrm{Cu}$ and $\mathrm{Fe}$ concentrations in CNS is not sufficient to initiate $A \beta$ and tau precipitation. Thus, the initiation of $A \beta$ and tau related pathology must be caused by other stimuli, e.g. by long-term exposure to ROS or AGE, although trapping of $\mathrm{Cu}$ and $\mathrm{Fe}$ may enhance the progression.

Surprisingly, the brains of AD patients are not characterized by increased overall $\mathrm{Cu}$ concentrations 
(Exley et al. 2012; Schrag et al. 2011). However, a hypothesis claims that $\mathrm{Cu}$ is removed from various regions of the brain and trapped by $A \beta$ in the pathological plaques. Consistent with this, Maynard et al. (2002) reported that overexpression of the carboxyl-terminal fragment of APP with copperbinding $A \beta$-fragment in a transgenic mouse model resulted in a redistribution of $\mathrm{Cu}$ in the brain and progression of amyloid precipitation (Maynard et al. 2002). Total $\mathrm{Cu}$ remains unchanged in serum or cerebrum in $\mathrm{AD}$ patients when compared to healthy subjects (Bucossi et al. 2011), but its intracerebral distribution appears to be deranged.

Metal chelation as a therapeutic strategy

Dyshomeostasis of $\mathrm{Cu}$ and $\mathrm{Fe}$ in $\mathrm{AD}$ brains with accumulation of these metals in plaques and tangles may be accompanied by increased generation of ROS and progression of tissue damage. An early study showed that Fe chelation with deferoxamine $(125 \mathrm{mg}$ i.m. twice daily/5 days/week for 24 months) resulted in a significant reduction in the rate of decline of daily living skills in $48 \mathrm{AD}$ patients, but not in $\mathrm{AD}$ patients receiving placebo (McLachlan et al. 1993). Since then, only few chelating agents have been examined in clinical trials for the treatment of $\mathrm{AD}$, viz. clioquinol (iodochlorhydroxyquin) and PBT2 (5,7-dichloro-2(dimethylamino)-methyl)-8-hydroxyquinoline). Both agents bind local excesses of $\mathrm{Cu}$ and $\mathrm{Fe}$ in the brain, thereby presumably retarding the amyloid plaque progression (Bush 2002; Lannfelt et al. 2008; Ritchie et al. 2003). Although none of these studies showed clear clinical effect of chelation therapy in $\mathrm{AD}$, post hoc analyses appeared promising (Barnham and Bush 2014; Faux et al. 2010), and indicated that the hydroxyquinoline derivatives act as chaperonemimetic agents (Ayton et al. 2015). However, longterm use of hydroxyquinolines may give rise to serious side effects, and the search for less toxic agents is encouraged (Meade 1975).

Selenium as a protective and chelating agent

Selenium is a trace element crucial to cerebral functions. During Se depletion brain $\mathrm{Se}$ is maintained at the expense of other tissues whereas severe Se deficiency causes irreversible brain injury (Burk and Hill 2009). The circulating Se transporter, selenoprotein P (SEPP), appears to have a special role in the delivery of Se to the brain and neurons by entering via the multifunctional apolipoprotein E receptor 2 (ApoER2), a member of the lipoprotein-receptor family that is expressed in neurons in the brain (Burk et al. 2014). In the brain SEPP is primarily provided by synthesis in the astroglial cells. Mice without the machinery for SEPP synthesis under Se deficient conditions develop spasticity, abnormal movements, and seizures (Schweizer et al. 2004). While SEPP is the important extracellular selenoprotein, glutathione peroxidases (GPx1 acting on soluble cytosolic peroxides and GPx4 acting on membrane bound phospholipid peroxides) are important intracellular antioxidants in neurons and glia (Mitozo et al. 2011; Zhang et al. 2010). Also thioredoxin reductases are abundantly expressed in neurons and glia (Godoy et al. 2011). These selenoproteins contain Se in the form of amino acid selenocysteine (SeCys) which differs from cysteine by a single atom (Se vs. S), conferring a lower pKa (5.2 vs. 8.3) and higher reactivity to its functional selenol group. GPx contains only one SeCys residue, whereas SEPP contains 10 SeCys residues conferring a high chelator affinity to $\mathrm{Cu}(\mathrm{I})$ (Aaseth et al. 2016). In vitro SEPP has been shown to inhibit $\mathrm{Cu}$ induced $A \beta$ aggregation (Du et al. 2014b).

Evidence from human studies suggests a role for $\mathrm{Se}$ and selenoproteins in protection against cognitive decline. In the InCHIANTI cohort study of 1012 Italian participants aged 65 years or older, 59 performancebased assessment scores of coordination as well as the MMSE-score were significantly reduced in participants with low plasma Se $(<66.7 \mu \mathrm{g} / \mathrm{L})$ compared to those with higher $(>82.3 \mu \mathrm{g} / \mathrm{L}$ ) concentrations (Shahar et al. 2010). In the French EVA cohort of 1166 people aged 60-70 years (Berr et al. 2000) a $58 \%$ increased odds ratio of cognitive decline was recorded over four years in participants with a Se concentration in the 1st quartile $(<75.8 \mu \mathrm{g} / \mathrm{L})$ at baseline, as compared to a mean baseline plasma Se level of $86.9 \mu \mathrm{g} / \mathrm{L}$. Furthermore, cognitive decline was significantly associated with the magnitude of plasma Se decrease over nine years, which attained a decrease of $0.35 \mu \mathrm{g} / \mathrm{L}$ in one of the subgroups (Akbaraly et al. 2007). In a crosssectional survey of 2000 rural Chinese adults aged 65 years or older, low nail Se concentration was significantly associated with low cognitive scores in four of five tests, with a dose-response effect across Se quintiles (Gao et al. 2007). From Spain GonzalezDominguez et al. (2014) in a cross sectional study 
found lower Se levels in serum from $\mathrm{AD}$ patients $(121 \mu \mathrm{g} / \mathrm{L})$ in comparison to elderly MCI subjects $(127 \mu \mathrm{g} / \mathrm{L})($ Gonzalez-Dominguez et al. 2014). Also in patients with very mild AD (MMSE score $\geq 20$ ) Se levels in plasma were reported to be lower ( 82.2 vs. $93.2 \mu \mathrm{g} / \mathrm{L})$ compared to healthy age-matched elderly subjects in a Dutch cross-sectional study (Olde Rikkert et al. 2014).

In several European countries the daily Se intake is too low to obtain optimal function of important selenoenzymes (Fig. 2). The European data on increased cognitive decline at low Se status are in agreement with cross-sectional studies from Brazil and Turkey (Cardoso et al. 2010; Vural et al. 2010). On the other hand a study from India did not find low Se concentrations (174 vs. $188 \mu \mathrm{g} / \mathrm{kg}$ ) in patients with AD compared with healthy controls, but their Se levels were higher than the European levels (Krishnan and Rani 2014). Supplementation with compounds containing Se has shown potential for stimulating cognitive improvement (Kesse-Guyot et al. 2011; Scheltens et al. 2010). Cardoso et al. (2015) reported that the daily supplement with one Brazilian nut, corresponding to about $280 \mu \mathrm{g}$ Se/day, over 6 months was associated with cognitive performance improvement when given to patients with mild cognitive impairment (Cardoso et al. 2015).

Animal models and in vitro Se studies are in accordance with the observations from human surveys. Sodium selenate treatment reduced tau phosphorylation, by activation of protein phosphatase $2 \mathrm{~A}$ (PP2A), both in cell cultures and tau transgenic animal models (Corcoran et al. 2010b; van Eersel et al. 2010). This treatment prevented and reversed memory and motor deficits; neurofibrillary tangles formation and neurodegeneration in transgenic animals (Ishrat et al. 2009; van Eersel et al. 2010) at a dose of $1 \mathrm{mg} / \mathrm{kg}$ bw selenate (van Eersel et al. 2010). Treatment of transgenic $\mathrm{AD}$ mice with selenomethionine resulted in reduced total and phosphorylated tau, lower inflammatory biomarkers and improvement in cognition (Song et al. 2014).

A hypothesis for protection by selenoproteins

High extracellular SEPP levels of have been found in the brain (Bellinger et al. 2008; Steinbrenner and Sies 2013; Takemoto et al. 2010). All regions of mouse

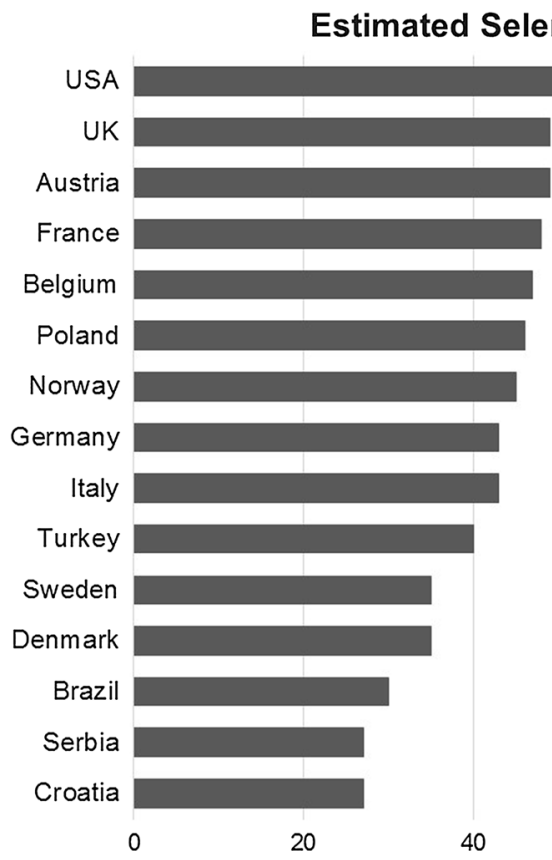

Fig. 2 Average daily selenium intake in various countries. Data are from Birgisdottir et al. (2013), Ellingsen et al. (2009), Fairweather-Tait et al. (2011), Vanderlelie and Perkins (2011); Rayman (2005), Maihara et al. (2004), Stoffaneller and Morse

(2015). Because of import of wheat, Norway is slightly higher in Se intake than Denmark and Sweden. Optimization of selenoprotein $\mathrm{P}$ requires a daily intake of about $105 \mu \mathrm{g}$ (Hurst et al. 2010), indicated by a dotted line 
brain appear to be dependent on SEPP for maintenance of proper functions (Nakayama et al. 2007). Knockout of SEPP or ApoER2 in mice resulted in neurological dysfunction, particularly when fed a low Se diet, and it appears that under low Se supply these two proteins are necessary to maintain $\mathrm{Se}$ in the brain and prevent neuron degeneration (Burk et al. 2014; Caito et al. 2011; Steinbrenner and Sies 2013; Valentine et al. 2008). Regional progression of neurodegeneration in the brain of the SEPP knock-out mice has been studied in order to map neuronal cell death, and evaluate neuronal structural changes within the hippocampus (Caito et al. 2011). Neurodegeneration was found to be present in all studied brain regions in the knock-out animals fed the Se-deficient diet (Caito et al. 2011). The neurodegeneration was predominantly axonal, however neuronal bodies in the somatosensory cortex and lateral striatum appeared also to be severely deteriorated. Morphological analysis of the hippocampus revealed decreased dendritic length, density and functionally. A defect in the long term potentiation of the hippocampus, essential for memory imprinting, was also noted. These findings are in line with the hypothesis that Se deficiency contributes to functional deficits seen in AD (Caito et al. 2011; Peters et al. 2006).

The expression of SEPP in postmortem tissue from individuals with the hallmark lesions of $\mathrm{AD}$ and individuals without these lesions has been examined (Bellinger et al. 2008). SEPP immunoreactivity was co-localized with $\mathrm{A} \beta$ plaques and neurofibrillary tangles (Bellinger et al. 2008). These observations suggest some form of interaction between SEPP and $\mathrm{A} \beta$, leading to complex formation. Like SEPP, $\mathrm{A} \beta$ is also a strong metal chelator, binding for instance $\mathrm{Cu}$ (2016; Ma et al. 2006; Myhre et al. 2013; Syme et al. 2004), and Fe (Myhre et al. 2013). Ternary complexes can be formed between metal cations, $\mathrm{A} \beta$ and SEPP and such complexes are presumably less toxic than A $\beta$-metal complexes alone. Since $\mathrm{Cu}$ is one of the metals abundant in $\mathrm{A} \beta$ (Myhre et al. 2013) and $\mathrm{Cu}$ (I) binds very strongly to Se atoms, a ternary complex between $\mathrm{Cu}(\mathrm{I}), \mathrm{A} \beta$ and SEPP can explain the colocalization of SEPP with $\mathrm{A} \beta$ in $\mathrm{AD}$ (Aaseth et al. 2016). SEPP also contains two His-rich regions that contribute to its affinity for $\mathrm{Cu}$ and $\mathrm{Fe}$.

Thus SEPP chelation blocks metal-mediated A $\beta$ aggregation and ROS generation [110]. The trapping of SEPP by $\mathrm{A} \beta$-plaques may reduce its availability for the synthesis of intracellular selenoproteins including thioredoxin reductase (TrxR) and GPx. Together with glutathione (GSH) these intra-neuronal selenoenzymes operate as intracellular antioxidants, thereby inhibiting tau aggregation (Du et al. 2014a). Selenium treatment has been reported to reduce tau phosphorylation in transgenic rats (Yim et al. 2009). In healthy brains the microtubule-associated tau protein regulates microtubule dynamics (Yuraszeck et al. 2010). The exact role of GPx and its cofactor GSH for protection of microtubules has yet not been fully elucidated. It should be emphasized here that microtubules are essential parts of the cytoskeleton, thereby maintaining the three-dimensional structure of the neurons. Microtubules play crucial roles in a variety of cellular events, including axonal and dendritic transport and neuronal growth and differentiation (Lasek 1981). Each tubulin monomer has at least 13 free $\mathrm{SH}$ groups, and it presumably needs protection against oxidative derangement by the GPx-GSH-system (Fig. 3). The intracellular protector GSH (reduced form) can be optimized by $\mathrm{N}$-acetylcysteine supplementation. A study on AD patients supplemented with $\mathrm{N}$-acetylcysteine over a six month period reported improved performance on memory tests (Adair et al. 2001).

Apparently, optimal function of GPx and SEPP is necessary for protection against the cognitive decline characterizing $\mathrm{AD}$. Optimal function requires higher intakes of Se than officially recommended in Nordic and other European countries. Selenium intake in

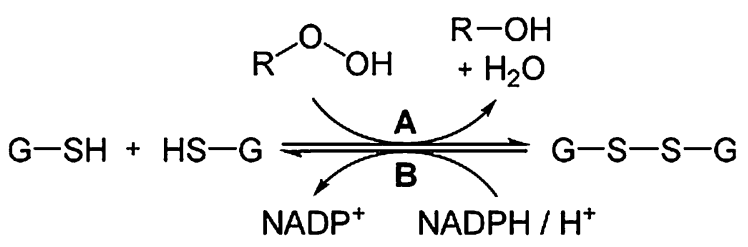

Fig. 3 Intracellular detoxification by GPx and GSH. Toxic peroxides $(\mathrm{R}-\mathrm{OOH})$ are reduced to non-toxic $\mathrm{R}-\mathrm{OH}$ by the action of the selenoenzymes glutathione peroxidases (A) in the presence of adequate amounts of the co-factor GSH found intracellularly, in contrast to the negligible GSH-levels found extracellularly. GSH is oxidized to its disulphide GSSG in this reaction. The reduced form GSH is regenerated by intracellular glutathione reductase (B) in the presence of $\mathrm{NADPH}_{2}$. This same co-factor, GSH, can also detoxify the compounds glyoxal and methylglyoxal which are neurotoxic byproducts of glucose metabolism, particularly in cases of insulin resistance. The latter reaction requires the presence of the glyoxalase enzyme system (Aaseth et al. 2016) 
North-America and some other regions of the world are considerably higher than in Europe (Fig. 2), which might contribute to inconsistencies in the clinical evidence as to the role of Se supplementation (Du et al. 2016; Loef et al. 2011). Results from a Swedish study published in 2015 indicated improved vitality and overall score of health related quality-of-life as a result of intervention with $\mathrm{Se}$ and coenzyme $\mathrm{Q}_{10}$ to an elderly population with mean baseline plasma Se of $67 \mu \mathrm{g} / \mathrm{L}$ (Johansson et al. 2015). The same intervention study also demonstrated a decreased inflammatory activity as registered by the biomarkers sPselectin and hs-CRP (Alehagen et al. 2015). The Se supplement dose in this latter study was $200 \mu \mathrm{g} /$ day, given as selenized yeast. Another intervention that is in progress is the PREADVISE study carried out in the same regions of America as the SELECT study. Thus, the population under investigation has a baseline $\mathrm{Se}$ intake that is substantially higher than European intakes (Fig. 3). Participants included in PREADVISE had reported memory complaints at inclusion. The design was double-blind, placebo controlled and randomized, transformed into an observational cohort after discontinuation of supplementation in the SELECT parent trial. PREADVISE participants were assessed at 130 local clinical study sites in the United States, Canada, and Puerto Rico during the controlled trial phase, with a followed up by telephone from a centralized location during the observational phase (Kryscio et al. 2013). Unfortunately, results from this American study cannot be generalized to European populations with lower Se levels.

\section{Concluding remarks}

Accumulated evidence indicates that AD neuropathology involves multiple biological pathways. The amyloid cascade hypothesis has dominated the field for over 20 years, resulting in a large number of studies with focus on approaches to inhibit formation of and remove $\mathrm{A} \beta$ from senile plaques. Yet these trials have failed to demonstrate significant cognitive improvements in patients. Thus novel pharmacotherapies should not be limited to the postulate of the amyloid cascade hypothesis alone, since events occurring intracellularly may prove to be more important for an understanding of the pathology of AD.
Selenate can act as potent inhibitor of tau hyperphosphorylation, presumably by optimizing the functions of antioxidative selenoenzymes that protect the neuronal cytoskeleton. Several nutritional and lifestyle factors may be involved in $\mathrm{AD}$ progression and prevention and the preventive roles of intracellular selenoenzymes against derangement of microtubules and neuronal integrity in the hippocampal area are emphasized in this review. A prophylactic role of optimized Se intake is suggested. Primary prevention should aim at an adequate nutritional intake of Se securing optimal expression of selenoproteins.

A secondary prevention trial using Se supplementation at higher doses, e.g. $200 \mu \mathrm{g} /$ day, to overcome extracellular Se trapping by $A \beta$ in the brain, is of particular importance. Selenized yeast has been used in several clinical trials, although selenate, the primary species used in animal models, is also well tolerated and passes the blood brain barrier (Corcoran et al. 2010a). The intervention should be directed towards elderly with diagnosed MCI. in European regions with low baseline Se intake (Fig. 2), i.e. in Sweden and Norway.

\section{Compliance with ethical standards}

Conflict of interest The authors declare that they have no conflict of interest.

Open Access This article is distributed under the terms of the Creative Commons Attribution 4.0 International License (http:// creativecommons.org/licenses/by/4.0/), which permits unrestricted use, distribution, and reproduction in any medium, provided you give appropriate credit to the original author(s) and the source, provide a link to the Creative Commons license, and indicate if changes were made.

\section{References}

Aaseth J, Stoa-Birketvedt G (2000) Glutathione in overweight patients with poorly controlled tyoe 2 diabetes. J Trace Elements Exp Med 13:105-111

Aaseth J, Crisponi G, Andersen O (eds) (2016) Chelation therapy in the treatment of metal intoxication. Academic Press, Cambridge

Adair JC, Knoefel JE, Morgan N (2001) Controlled trial of $\mathrm{N}$-acetylcysteine for patients with probable Alzheimer's disease. Neurology 57:1515-1517

Akbaraly TN, Hininger-Favier I, Carriere I, Arnaud J, Gourlet V, Roussel AM, Berr C (2007) Plasma selenium over time and cognitive decline in the elderly. Epidemiology 18:52-58. doi:10.1097/01.ede.0000248202.83695.4e 
Alehagen U, Johansson P, Bjornstedt M, Rosen A, Dahlstrom U (2013) Cardiovascular mortality and N-terminal-proBNP reduced after combined selenium and coenzyme Q10 supplementation: a 5-year prospective randomized doubleblind placebo-controlled trial among elderly Swedish citizens. Int J Cardiol 167:1860-1866. doi:10.1016/j.ijcard. 2012.04.156

Alehagen U, Lindahl TL, Aaseth J, Svensson E, Johansson P (2015) Levels of sP-selectin and hs-CRP Decrease with Dietary Intervention with selenium and coenzyme Q10 Combined: a secondary analysis of a randomized clinical trial. PLoS One 10:e0137680. doi:10.1371/journal.pone. 0137680

Alexander J (2014) Handbook on the Toxicology of Metals. Academic Press, Cambridge

Altamura S, Muckenthaler MU (2009) Iron toxicity in diseases of aging: Alzheimer's disease, Parkinson's disease and atherosclerosis. J Alzheimers Dis 16:879-895. doi:10. 3233/JAD-2009-1010

Alzheimer's A (2015) Alzheimer's disease facts and figures. Alzheimers Dement 11:332-384

Areosa SA, Sherriff F, McShane R (2005) Memantine for dementia. Cochrane Database Syst Rev. doi:10.1002/ 14651858.CD003154.pub4

Ayton S, Lei P, Bush AI (2015) Biometals and their therapeutic implications in Alzheimer's disease. J Am Soc Exp NeuroTher 12:109-120. doi:10.1007/s13311-014-0312-z

Barnham KJ, Bush AI (2014) Biological metals and metal-targeting compounds in major neurodegenerative diseases. Chem Soc Rev 43:6727-6749. doi:10.1039/c4cs00138a

Bellinger FP, He QP, Bellinger MT, Lin Y, Raman AV, White LR, Berry MJ (2008) Association of selenoprotein p with Alzheimer's pathology in human cortex. J Alzheimers Dis 15:465-472

Berr C, Balansard B, Arnaud J, Roussel AM, Alperovitch A (2000) Cognitive decline is associated with systemic oxidative stress: the EVA study. Etude du Vieillissement Arteriel J Am Geriatr Soc 48:1285-1291

Birgisdottir BE et al (2013) Essential and toxic element concentrations in blood and urine and their associations with diet: results from a Norwegian population study including high-consumers of seafood and game. Science Total Environ 463-464:836-844. doi:10.1016/j.scitotenv.2013. 06.078

Brewer GJ, Kanzer SH, Zimmerman EA, Celmins DF, Heckman SM, Dick R (2010) Copper and ceruloplasmin abnormalities in Alzheimer's disease. Am J Alzheimers Dis Other Dement 25:490-497. doi:10.1177/1533317510375083

Bucossi S et al (2011) Copper in Alzheimer's disease: a metaanalysis of serum, plasma, and cerebrospinal fluid studies. J Alzheimers Dis 24:175-185. doi:10.3233/JAD-2010101473

Burk RF, Hill KE (2009) Selenoprotein P-expression, functions, and roles in mammals. Biochim Biophys Acta 1790:1441-1447. doi:10.1016/j.bbagen.2009.03.026

Burk RF, Hill KE, Motley AK, Winfrey VP, Kurokawa S, Mitchell SL, Zhang W (2014) Selenoprotein P and apolipoprotein $\mathrm{E}$ receptor-2 interact at the blood-brain barrier and also within the brain to maintain an essential selenium pool that protects against neurodegeneration. FASEB J 28:3579-3588. doi:10.1096/fj.14-252874
Bush AI (2002) Metal complexing agents as therapies for Alzheimer's disease. Neurobiol Aging 23:1031-1038

Caito SW, Milatovic D, Hill KE, Aschner M, Burk RF, Valentine WM (2011) Progression of neurodegeneration and morphologic changes in the brains of juvenile mice with selenoprotein P deleted. Brain Res 1398:1-12. doi:10. 1016/j.brainres.2011.04.046

Campion D et al (1999) Early-onset autosomal dominant Alzheimer disease: prevalence, genetic heterogeneity, and mutation spectrum. Am J Hum Genet 65:664-670. doi:10. 1086/302553

Cardoso BR, Ong TP, Jacob-Filho W, Jaluul O, Freitas MI, Cozzolino SM (2010) Nutritional status of selenium in Alzheimer's disease patients. Br J Nutr 103:803-806. doi:10.1017/S0007114509992832

Cardoso BR, Roberts BR, Bush AI, Hare DJ (2015) Selenium, selenoproteins and neurodegenerative diseases. Metallomics 7:1213-1228. doi:10.1039/c5mt00075k

Castello MA, Soriano S (2014) On the origin of Alzheimer's disease. Trials and tribulations of the amyloid hypothesis. Ageing Res Rev 13:10-12. doi:10.1016/j.arr.2013.10.001

Clarke JR et al (2015) Alzheimer-associated Abeta oligomers impact the central nervous system to induce peripheral metabolic deregulation. EMBO Mol Med 7:190-210. doi:10.15252/emmm.201404183

Corcoran NM, Hovens CM, Michael M, Rosenthal MA, Costello AJ (2010a) Open-label, phase I dose-escalation study of sodium selenate, a novel activator of PP2A, in patients with castration-resistant prostate cancer. $\mathrm{Br} \mathrm{J}$ Cancer 103:462-468. doi:10.1038/sj.bjc.6605798

Corcoran NM et al (2010b) Sodium selenate specifically activates PP2A phosphatase, dephosphorylates tau and reverses memory deficits in an Alzheimer's disease model. J Clin Neurosci 17:1025-1033. doi:10.1016/j.jocn.2010. 04.020

Dalla Puppa L, Savaskan NE, Brauer AU, Behne D, Kyriakopoulos A (2007) The role of selenite on microglial migration. Ann N Y Acad Sci 1096:179-183. doi:10.1196/ annals.1397.084

Drachman DA (2014) The amyloid hypothesis, time to move on: amyloid is the downstream result, not cause, of Alzheimer's disease. Alzheimers Dement 10:372-380. doi:10. 1016/j.jalz.2013.11.003

Du X, Qiu S, Wang Z, Wang R, Wang C, Tian J, Liu Q (2014a) Direct interaction between selenoprotein $\mathrm{P}$ and tubulin. Int J Mol Sci 15:10199-10214. doi:10.3390/ijms 150610199

Du X, Wang Z, Zheng Y, Li H, Ni J, Liu Q (2014b) Inhibitory effect of selenoprotein $\mathrm{P}$ on $\mathrm{Cu}(+) / \mathrm{Cu}(2+)$-induced $\mathrm{A} \beta 42$ aggregation and toxicity. Inorg Chem 53:1672-1678. doi:10.1021/ic4028282

Du X, Wang C, Liu Q (2016) Potential Roles of Selenium and Selenoproteins in the Prevention of Alzheimer's Disease. Curr Top Med Chem 16:835-848

ElAli A, Rivest S (2016) Microglia in Alzheimer's disease: a multifaceted relationship. Brain Behav Immun 55:138-150. doi:10.1016/j.bbi.2015.07.021

Ellingsen DG, Thomassen Y, Rustad P, Molander P, Aaseth J (2009) The time-trend and the relation between smoking and circulating selenium concentrations in Norway. J Trace Elem Med Biol 23:107-115. doi:10.1016/j.jtemb.2009.01. 004 
Exley C, House E, Polwart A, Esiri MM (2012) Brain burdens of aluminum, iron, and copper and their relationships with amyloid-beta pathology in 60 human brains. J Alzheimers Dis 31:725-730. doi:10.3233/JAD-2012-120766

Fairweather-Tait SJ, Bao Y, Broadley MR, Collings R, Ford D, Hesketh JE, Hurst R (2011) Selenium in human health and disease. Antioxid Redox Signal 14:1337-1383. doi:10. 1089/ars.2010.3275

Faux NG et al (2010) PBT2 rapidly improves cognition in Alzheimer's disease: additional phase II analyses. J Alzheimers Dis 20:509-516. doi:10.3233/JAD-2010-1390

Gaggelli E, Kozlowski H, Valensin D, Valensin G (2006) Copper homeostasis and neurodegenerative disorders (Alzheimer's, prion, and Parkinson's diseases and amyotrophic lateral sclerosis). Chem Rev 106:1995-2044. doi: $10.1021 / \mathrm{cr} 040410 \mathrm{w}$

Gao S et al (2007) Selenium level and cognitive function in rural elderly Chinese. Am J Epidemiol 165:955-965. doi:10. 1093/aje/kwk073

Gilman S et al (2005) Clinical effects of $A \beta$ immunization (AN1792) in patients with AD in an interrupted trial. Neurology 64:1553-1562. doi:10.1212/01.WNL.0000159740. 16984.3C

Giri M, Zhang M, Lu Y (2016) Genes associated with Alzheimer's disease: an overview and current status. Clin Interv Aging 11:665-681. doi:10.2147/CIA.S105769

Godoy JR et al (2011) Redox atlas of the mouse: Immunohistochemical detection of glutaredoxin-, peroxiredoxin-, and thioredoxin-family proteins in various tissues of the laboratory mouse. Biochim Biophys Acta 1810:2-92. doi:10. 1016/j.bbagen.2010.05.006

Gold $\mathrm{M}$ et al (2010) Rosiglitazone monotherapy in mild-tomoderate Alzheimer's disease: results from a randomized, double-blind, placebo-controlled phase III study. Dement Geriatr Cogn Disord 30:131-146. doi:10.1159/000318845

Gonzalez-Cuyar LF et al (2008) Redox active iron accumulation in aceruloplasminemia. Neuropathology 28:466-471. doi:10.1111/j.1440-1789.2008.00901.x

Gonzalez-Dominguez R, Garcia-Barrera T, Gomez-Ariza JL (2014) Homeostasis of metals in the progression of Alzheimer's disease. Biometals 27:539-549. doi:10.1007/ s10534-014-9728-5

Hafting T, Fyhn M, Molden S, Moser MB, Moser EI (2005) Microstructure of a spatial map in the entorhinal cortex. Nature 436:801-806. doi:10.1038/nature03721

Hardy J, Selkoe DJ (2002) The amyloid hypothesis of Alzheimer's disease: progress and problems on the road to therapeutics. Science 297:353-356. doi:10.1126/science.1072994

Hochgrafe K et al (2015) Preventive methylene blue treatment preserves cognition in mice expressing full-length proaggregant human Tau. Acta Neuropathol Commun 3:25. doi:10.1186/s40478-015-0204-4

Hokama $\mathrm{M}$ et al (2014) Altered expression of diabetes-related genes in Alzheimer's disease brains: the Hisayama study. Cereb Cortex 24:2476-2488. doi:10.1093/cercor/bht101

Horoupian DS, Sternlieb I, Scheinberg IH (1988) Neuropathological findings in penicillamine-treated patients with Wilson's disease. Clin Neuropathol 7:62-67

Hurst R et al (2010) Establishing optimal selenium status: results of a randomized, double-blind, placebo-controlled trial. Am J Clin Nutr 91:923-931. doi:10.3945/ajcn.2009. 28169

Ishrat T et al (2009) Selenium prevents cognitive decline and oxidative damage in rat model of streptozotocin-induced experimental dementia of Alzheimer's type. Brain Res 1281:117-127. doi:10.1016/j.brainres.2009.04.010

Iwanski S, Seniow J, Lesniak M, Litwin T, Czlonkowska A (2015) Diverse attention deficits in patients with neurologically symptomatic and asymptomatic Wilson's disease. Neuropsychology 29:25-30. doi:10.1037/neu0000103

Jager T, Drexler H, Goen T (2016) Human metabolism and renal excretion of selenium compounds after oral ingestion of sodium selenate dependent on trimethylselenium ion (TMSe) status. Arch Toxicol 90:149-158. doi:10.1007/ s00204-014-1380-x

Johansson P, Dahlstrom O, Dahlstrom U, Alehagen U (2015) Improved health-related quality of life, and more days out of hospital with supplementation with selenium and coenzyme Q10 combined. Results from a double blind, placebo-controlled prospective study. J Nutr Health Aging 19:870-877. doi:10.1007/s12603-015-0509-9

Jonsson T et al (2012) A mutation in APP protects against Alzheimer's disease and age-related cognitive decline. Nature 488:96-99. doi:10.1038/nature11283

Jonsson T et al (2013) A coding mutation in APP protects against Alzheimeŕs disease and age-related cognitive decline. Alzheimeŕs Demen J Alzheimeŕs Assoc 9:P826P827

Kaneko K, Hineno A, Yoshida K, Ohara S, Morita H, Ikeda S (2012) Extensive brain pathology in a patient with aceruloplasminemia with a prolonged duration of illness. Hum Pathol 43:451-456. doi:10.1016/j.humpath.2011.05.016

Kesse-Guyot E et al (2011) French adults' cognitive performance after daily supplementation with antioxidant vitamins and minerals at nutritional doses: a post hoc analysis of the supplementation in vitamins and mineral antioxidants (SU.VI.MAX) trial. Am J Clin Nutr 94:892-899. doi:10.3945/ajen.110.007815

Kivipelto $\mathrm{M}$ et al (2005) Obesity and vascular risk factors at midlife and the risk of dementia and Alzheimer disease. Arch Neurol 62:1556-1560. doi:10.1001/archneur.62.10. 1556

Konishi K et al (2015) Hypothesis of endogenous anticholinergic activity in Alzheimer's disease. Neurodegener Dis 15:149-156. doi:10.1159/000381511

Kono S (2013) Aceruloplasminemia: an update. Int Rev Neurobiol 110:125-151. doi:10.1016/B978-0-12-410502-7. 00007-7

Krishnan S, Rani P (2014) Evaluation of selenium, redox status and their association with plasma amyloid/tau in Alzheimer's disease. Biol Trace Elem Res 158:158-165. doi:10. 1007/s12011-014-9930-x

Kryscio RJ et al (2013) A randomized controlled Alzheimer's disease prevention trial's evolution into an exposure trial: the PREADViSE Trial. J Nutr Health Aging 17:72-75. doi:10.1007/s12603-012-0083-3

Kuhla B, Luth HJ, Haferburg D, Boeck K, Arendt T, Munch G (2005) Methylglyoxal, glyoxal, and their detoxification in Alzheimer's disease. Ann N Y Acad Sci 1043:211-216. doi:10.1196/annals.1333.026 
Kumar-Singh S et al (2006) Mean age-of-onset of familial Alzheimer disease caused by presenilin mutations correlates with both increased $A \beta 42$ and decreased $A \beta 40$. Hum Mutat 27:686-695. doi:10.1002/humu.20336

Lannfelt L et al (2008) Safety, efficacy, and biomarker findings of PBT2 in targeting A $\beta$ as a modifying therapy for Alzheimer's disease: a phase IIa, double-blind, randomised, placebo-controlled trial. Lancet Neurol 7:779-786. doi:10. 1016/S1474-4422(08)70167-4

Lasek RJ (1981) The dynamic ordering of neuronal cytoskeletons. Neurosci Res Progr Bull 19:7-32

Li J, Liu D, Sun L, Lu Y, Zhang Z (2012) Advanced glycation end products and neurodegenerative diseases: mechanisms and perspective. J Neurol Sci 317:1-5. doi:10.1016/j.jns. 2012.02.018

Lim HK et al (2012) Relationships between hippocampal shape and cognitive performances in drug-naive patients with Alzheimer's disease. Neurosci Lett 516:124-129. doi:10. 1016/j.neulet.2012.03.072

Loef M, Schrauzer GN, Walach H (2011) Selenium and Alzheimer's disease: a systematic review. J Alzheimers Dis 26:81-104. doi:10.3233/JAD-2011-110414

Lourenco MV et al (2013) TNF-alpha mediates PKR-dependent memory impairment and brain IRS-1 inhibition induced by Alzheimer's beta-amyloid oligomers in mice and monkeys. Cell Metab 18:831-843. doi:10.1016/j.cmet.2013.11.002

Ma QF et al (2006) Characterization of copper binding to the peptide amyloid- $\beta(1-16)$ associated with Alzheimer's disease. Biopolymers 83:20-31. doi:10.1002/bip.20523

Maihara VA, Gonzaga IB, Silva VL, Fávaro DI, Vasconcellos MBA, Cozzolino SMF (2004) Daily dietary selenium intake of selected Brazilian population groups. J Radioanal Nucl Chem 259:465-468

Mawuenyega KG, Kasten T, Sigurdson W, Bateman RJ (2013) Amyloid-beta isoform metabolism quantitation by stable isotope-labeled kinetics. Anal Biochem 440:56-62. doi:10.1016/j.ab.2013.04.031

Maynard CJ et al (2002) Overexpression of Alzheimer's disease amyloid-beta opposes the age-dependent elevations of brain copper and iron. J Biol Chem 277:44670-44676. doi:10.1074/jbc.M204379200

McLachlan DR, Smith WL, Kruck TP (1993) Desferrioxamine and Alzheimer's disease: video home behavior assessment of clinical course and measures of brain aluminum. Ther Drug Monit 15:602-607

Meade TW (1975) Subacute myelo-optic neuropathy and clioquinol. An epidemiological case-history for diagnosis. Br J Prev Soc Med 29:157-169

Meenakshi-Sundaram S, Mahadevan A, Taly AB, Arunodaya GR, Swamy HS, Shankar SK (2008) Wilson's disease: a clinico-neuropathological autopsy study. J Clin Neurosci 15:409-417. doi:10.1016/j.jocn.2006.07.017

Mehta DC, Short JL, Hilmer SN, Nicolazzo JA (2015) Drug access to the central nervous system in Alzheimer's disease: preclinical and clinical insights. Pharm Res 32:819-839. doi:10.1007/s11095-014-1522-0

Mitozo PA et al (2011) A study of the relative importance of the peroxiredoxin-, catalase-, and glutathione-dependent systems in neural peroxide metabolism. Free Radic Biol Med 51:69-77. doi:10.1016/j.freeradbiomed.2011.03.017
Morita H et al (1995) Hereditary ceruloplasmin deficiency with hemosiderosis: a clinicopathological study of a Japanese family. Ann Neurol 37:646-656. doi:10.1002/ana.410370515

Myhre O, Utkilen H, Duale N, Brunborg G, Hofer T (2013) Metal dyshomeostasis and inflammation in Alzheimer's and Parkinson's diseases: possible impact of environmental exposures. Oxid Med Cell Longev 2013:726954. doi:10.1155/2013/726954

Nakayama A, Hill KE, Austin LM, Motley AK, Burk RF (2007) All regions of mouse brain are dependent on selenoprotein P for maintenance of selenium. J Nutr 137:690-693

Olde Rikkert MG et al (2014) Differences in nutritional status between very mild Alzheimer's disease patients and healthy controls. J Alzheimers Dis 41:261-271. doi:10.3233/ JAD-131892

Panza F, Solfrizzi V, Imbimbo BP, Tortelli R, Santamato A, Logroscino G (2014) Amyloid-based immunotherapy for Alzheimer's disease in the time of prevention trials: the way forward. Expert Rev Clin Immunol 10:405-419. doi:10.1586/1744666X.2014.883921

Parsons CG, Stoffler A, Danysz W (2007) Memantine: a NMDA receptor antagonist that improves memory by restoration of homeostasis in the glutamatergic system-too little activation is bad, too much is even worse. Neuropharmacology 53:699-723. doi:10.1016/j.neuropharm.2007.07.013

Pasqualetti P et al (2009) A randomized controlled study on effects of ibuprofen on cognitive progression of Alzheimer's disease. Aging Clin Exp Res 21:102-110

Patel BN, Dunn RJ, Jeong SY, Zhu Q, Julien JP, David S (2002) Ceruloplasmin regulates iron levels in the CNS and prevents free radical injury. J Neurosci 22:6578-6586

Peters MM, Hill KE, Burk RF, Weeber EJ (2006) Altered hippocampus synaptic function in selenoprotein $\mathrm{P}$ deficient mice. Mol Neurodegener 1:12. doi:10.1186/1750-1326-112

Priller C, Bauer T, Mitteregger G, Krebs B, Kretzschmar HA, Herms J (2006) Synapse formation and function is modulated by the amyloid precursor protein. J Neurosci 26:7212-7221. doi:10.1523/JNEUROSCI.1450-06.2006

Prohaska JR, Gybina AA (2004) Intracellular copper transport in mammals. J Nutr 134:1003-1006

Puranik R et al (2016) A novel class of copper (II)- and zinc (II)bound non-steroidal anti-inflammatory drugs that inhibits acute inflammation in vivo. Cell Biosci 6:9. doi:10.1186/ s13578-016-0076-8

Rayman MP (2005) Selenium in cancer prevention: a review of the evidence and mechanism of action. Proc Nutr Soc 64:527-542

Risner ME et al (2006) Efficacy of rosiglitazone in a genetically defined population with mild-to-moderate Alzheimer's disease. Pharmacogenomics J 6:246-254. doi:10.1038/sj. tpj.6500369

Ritchie CW et al (2003) Metal-protein attenuation with iodochlorhydroxyquin (clioquinol) targeting $\mathrm{A} \beta$ amyloid deposition and toxicity in Alzheimer disease: a pilot phase 2 clinical trial. Arch Neurol 60:1685-1691. doi:10.1001/ archneur.60.12.1685

Salloway S et al (2014) Two phase 3 trials of bapineuzumab in mild-to-moderate Alzheimer's disease. N Engl J Med 370:322-333. doi:10.1056/NEJMoa1304839 
Scheltens P et al (2010) Efficacy of a medical food in mild Alzheimer's disease: a randomized, controlled trial. Alzheimers Dement 6(1-10):e11. doi:10.1016/j.jalz.2009.10.003

Schrag M, Mueller C, Oyoyo U, Smith MA, Kirsch WM (2011) Iron, zinc and copper in the Alzheimer's disease brain: a quantitative meta-analysis. Some insight on the influence of citation bias on scientific opinion. Prog Neurobiol 94:296-306. doi:10.1016/j.pneurobio.2011.05.001

Schweizer U, Brauer AU, Kohrle J, Nitsch R, Savaskan NE (2004) Selenium and brain function: a poorly recognized liaison. Brain Res Rev 45:164-178. doi:10.1016/j. brainresrev.2004.03.004

Shahar A, Patel KV, Semba RD, Bandinelli S, Shahar DR, Ferrucci L, Guralnik JM (2010) Plasma selenium is positively related to performance in neurological tasks assessing coordination and motor speed. Mov Disord 25:1909-1915. doi: $10.1002 / \mathrm{mds} .23218$

Shukla V, Skuntz S, Pant HC (2012) Deregulated Cdk5 activity is involved in inducing Alzheimer's disease. Arch Med Res 43:655-662. doi:10.1016/j.arcmed.2012.10.015

Song G et al (2014) Selenomethionine ameliorates cognitive decline, reduces tau hyperphosphorylation, and reverses synaptic deficit in the triple transgenic mouse model of Alzheimer's disease. J Alzheimers Dis 41:85-99. doi:10. 3233/JAD-131805

Sparks DL, Schreurs BG (2003) Trace amounts of copper in water induce beta-amyloid plaques and learning deficits in a rabbit model of Alzheimer's disease. Proc Natl Acad Sci U S A 100:11065-11069. doi:10.1073/pnas. 1832769100

Squitti R et al (2011) Free copper distinguishes mild cognitive impairment subjects from healthy elderly individuals. J Alzheimers Dis 23:239-248. doi:10.3233/JAD-2010101098

Steinbrenner H, Sies H (2013) Selenium homeostasis and antioxidant selenoproteins in brain: implications for disorders in the central nervous system. Arch Biochem Biophys 536:152-157. doi:10.1016/j.abb.2013.02.021

Stoffaneller R, Morse NL (2015) A review of dietary selenium intake and selenium status in Europe and the Middle East. Nutrients 7:1494-1537. doi:10.3390/nu7031494

Syme CD, Nadal RC, Rigby SE, Viles JH (2004) Copper binding to the amyloid- $\beta$ (A $\beta$ ) peptide associated with Alzheimer's disease: folding, coordination geometry, $\mathrm{pH}$ dependence, stoichiometry, and affinity of $\mathrm{A} \beta-(1-28)$ : insights from a range of complementary spectroscopic techniques. J Biol Chem 279:18169-18177. doi:10.1074/ jbc.M313572200

Takemoto AS, Berry MJ, Bellinger FP (2010) Role of selenoprotein P in Alzheimer's disease. Ethn Dis 20(1):92-95

Tata AM, Velluto L, D'Angelo C, Reale M (2014) Cholinergic system dysfunction and neurodegenerative diseases: cause or effect? CNS Neurol Disord Drug Targets 13:1294-1303

Tayeb HO, Murray ED, Price BH, Tarazi FI (2013) Bapineuzumab and solanezumab for Alzheimer's disease: is the 'amyloid cascade hypothesis' still alive? Expert Opin Biol Ther 13:1075-1084. doi:10.1517/14712598.2013.789856

Thornalley PJ, Langborg A, Minhas HS (1999) Formation of glyoxal, methylglyoxal and 3-deoxyglucosone in the glycation of proteins by glucose. Biochem J 344(1):109-116

Torsdottir G, Kristinsson J, Snaedal J, Johannesson T (2011) Ceruloplasmin and iron proteins in the serum of patients with Alzheimer's disease. Dement Geriatr Cogn Dis Extra 1:366-371. doi:10.1159/000330467

Valentine WM, Abel TW, Hill KE, Austin LM, Burk RF (2008) Neurodegeneration in mice resulting from loss of functional selenoprotein $\mathrm{P}$ or its receptor apolipoprotein $\mathrm{E}$ receptor 2. J Neuropathol Exp Neurol 67:68-77. doi:10. 1097/NEN.0b013e318160f347

van Eersel J, Ke YD, Liu X, Delerue F, Kril JJ, Gotz J, Ittner LM (2010) Sodium selenate mitigates tau pathology, neurodegeneration, and functional deficits in Alzheimer's disease models. Proc Natl Acad Sci 107:13888-13893. doi:10.1073/pnas.1009038107

Vanderlelie J, Perkins AV (2011) Selenium and preeclampsia: A global perspective. Pregnancy Hypertens 1:213-224. doi:10.1016/j.preghy.2011.07.001

Vural H, Demirin H, Kara Y, Eren I, Delibas N (2010) Alterations of plasma magnesium, copper, zinc, iron and selenium concentrations and some related erythrocyte antioxidant enzyme activities in patients with Alzheimer's disease. J Trace Elem Med Biol 24:169-173. doi:10.1016/j. jtemb.2010.02.002

Wallace TL, Bertrand D (2013) Importance of the nicotinic acetylcholine receptor system in the prefrontal cortex. Biochem Pharmacol 85:1713-1720. doi:10.1016/j.bcp. 2013.04.001

Ward RJ, Zucca FA, Duyn JH, Crichton RR, Zecca L (2014) The role of iron in brain ageing and neurodegenerative disorders. Lancet Neurol 13:1045-1060. doi:10.1016/S14744422(14)70117-6

Ward RJ, Dexter DT, Crichton RR (2015) Neurodegenerative diseases and therapeutic strategies using iron chelators. J Trace Elem Med Biol 31:267-273. doi:10.1016/j.jtemb. 2014.12.012

Wiessner C et al (2011) The second-generation active Abeta immunotherapy CAD106 reduces amyloid accumulation in APP transgenic mice while minimizing potential side effects. J Neurosci 31:9323-9331. doi:10.1523/JNEURO SCI.0293-11.2011

Xiang Z, Haroutunian V, Ho L, Purohit D, Pasinetti GM (2006) Microglia activation in the brain as inflammatory biomarker of Alzheimer's disease neuropathology and clinical dementia. Dis Markers 22:95-102

Yim SY et al (2009) ERK activation induced by selenium treatment significantly downregulates beta/gamma-secretase activity and Tau phosphorylation in the transgenic rat overexpressing human selenoprotein M. Int J Mol Med 24:91-96

Yuraszeck TM, Neveu P, Rodriguez-Fernandez M, Robinson A, Kosik KS, Doyle FJ 3rd (2010) Vulnerabilities in the tau network and the role of ultrasensitive points in tau pathophysiology. PLoS Comput Biol 6:e1000997. doi:10.1371/ journal.pcbi.1000997

Zhang S, Rocourt C, Cheng WH (2010) Selenoproteins and the aging brain. Mech Ageing Dev 131:253-260. doi:10.1016/ j.mad.2010.02.006

Zimmer ER, Kalinine E, Haas CB, Torrez VR, Souza DO, Muller AP, Portela LV (2012) Pretreatment with memantine prevents Alzheimer-like alterations induced by intrahippocampal okadaic acid administration in rats. Curr Alzheimer Res 9:1182-1190 